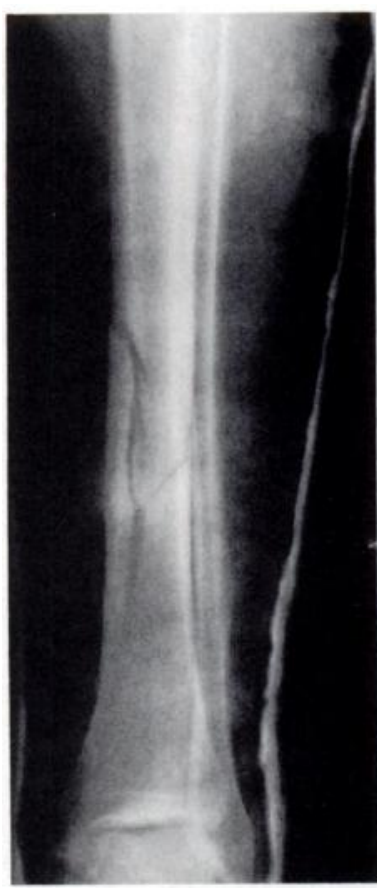

Fig. 1a

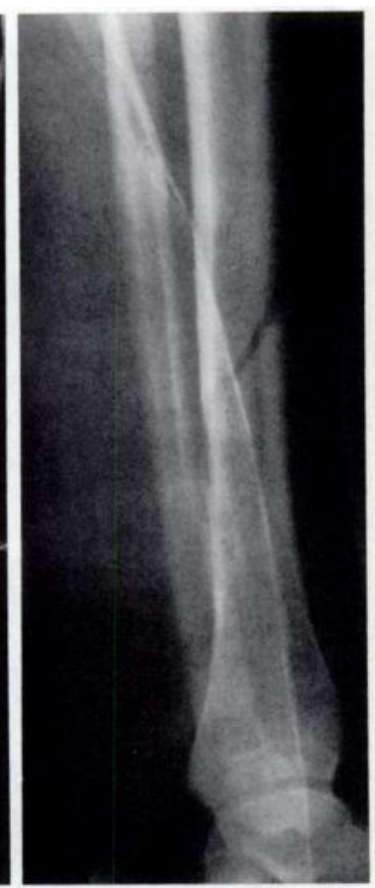

Fig. 1b

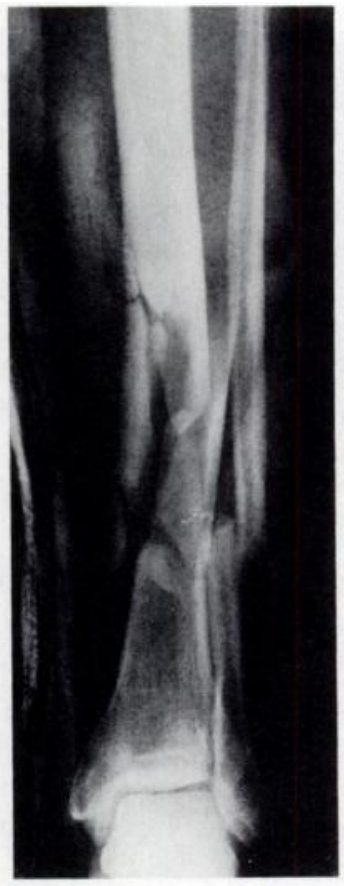

Fig. 2a

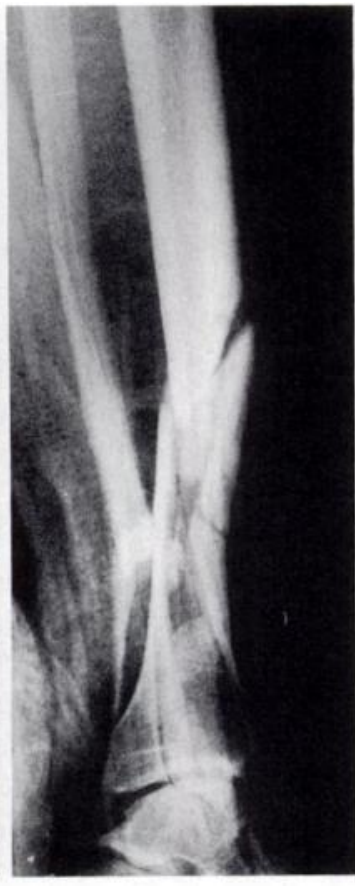

Fig. 2b

Professional golfers play frequently and may strike an average of 800 balls a week for 40 weeks of the year, driving them at over 130 miles per hour. The forces in the tibia are very unlikely to cause a traumatic fracture in normal bone (Paul, personal communication, 1993). The previous symptoms in both cases suggest that the major fractures were due to earlier stress fractures caused by repeated torsion of the left tibia at the end of right-handed drives. Persistent shin pain in professional golfers should be regarded as due to stress fracture and treated as such to avoid potentially major injury.

I am grateful to Mr A. W. G. Kinninmonth, Mr K. Mathur and Mr R. D. Pool for allowing me to report on their patients.

No benefits in any form have been received or will be received from a commercial party related directly or indirectly to the subject of this article.

\section{REFERENCES}

Devas MB. Stress fractures of the tibia in athletes or "shin soreness", J Bone Joint Surg [Br] 1958; 40-B:227-39.

Milgrom C, Giladi M, Simkin A, et al. The area moment of inertia of the tibia: a risk factor for stress fractures. J Biomech 1989; 22:1243-8.

Spector FC, Karlin JM, DeValentine S, Scurran BL, Silvani SL. Spiral fracture of the distal tibia: an unusual stress fracture.J Foot Surg 1983; 22:358-61.

\title{
COMPARISON OF MRI WITH BONE SCANNING FOR SUSPECTED HIP FRACTURE IN ELDERLY PATIENTS
}

\author{
P. D. EVANS, C. WILSON, K. LYONS
}

Most fractures of the femoral neck are readily diagnosed from the radiographs but in a few cases these are misleading. Isotope bone scans have been used to detect such occult

P. D. Evans, FRCS Orth, Senior Lecturer

C. Wilson, FRCS, Orthopaedic Registrar

Department of Traumatic and Orthopaedic Surgery

K. Lyons, FRCR, Consultant Radiologist

Department of Radiology

Cardiff Royal Infirmary, Cardiff CF2 ISZ, UK.

Correspondence to Mr P. D. Evans

(1)1994 British Editorial Society of Bone and Joint Surgery

0301-620X/94/1R78 \$2.00

J Bone Joint Surg [Br] 1994; 76-B:158-9.

Received 22 September 1992; Accepted 19 July 1993 fractures (Fairclough et al 1987). We performed a prospective study to compare MRI with isotope scanning.

During a six-month period, 230 elderly patients were admitted to our hospital with hip pain after a fall. In 193 of them, radiography revealed a fracture of the femoral neck; in the remaining 37 the radiographs were normal or showed only a fracture of the greater trochanter. These patients all had MRI; a five-minute sequence of T1-weighted coronal images of the hip was obtained. Where necessary STIR (short tau inversion recovery) and/or T2-weighted images were also obtained. The patients then had ${ }^{99 \mathrm{~m}} \mathrm{Tc}$ diphosphonate bone scans of the hip. This investigation was delayed until at least 48 hours after the fall to avoid false-positive results from soft-tissue bruising. 


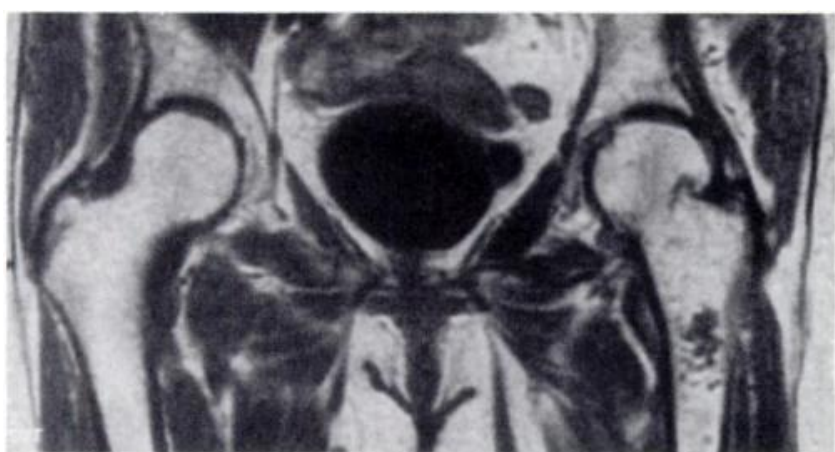

Fig. 1

Eight of the 37 patients with normal radiographs proved to have undisplaced femoral neck fractures. All eight fractures were diagnosed by MRI (Figs 1 and 2) but only six were seen by the isotope scan. The remaining 29 patients had no evidence of a femoral neck fracture; all were asymptomatic when they were reviewed three months after the injury.

Discussion. Isotope bone scanning was found by Fairclough et al (1987) to be a reliable aid to the identification of occult fractures of the femoral neck. It is, however, non-specific; a minor fracture of a trochanter can give the same appearance as a fracture of the femoral neck. It is also an invasive and time-consuming investigation. MRI has been used to identify stress fractures (Lee and Yao 1988) and occult femoral neck

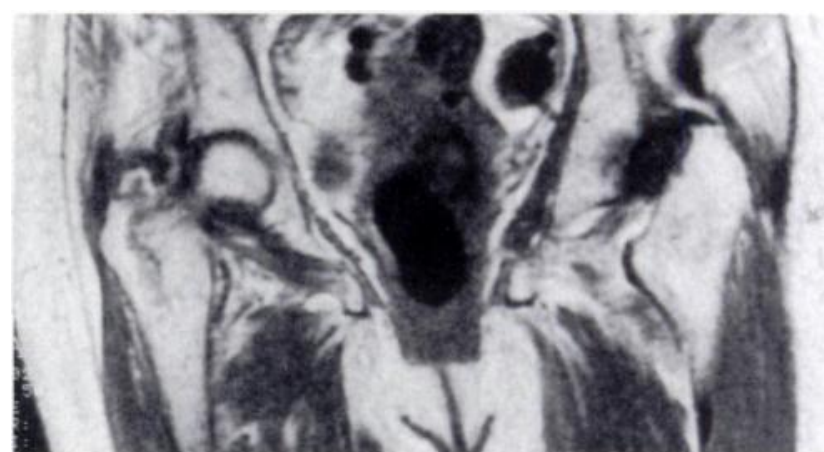

Fig. 2

fractures (Rizzo et al 1993). In our study MRI proved more accurate than radioisotope scanning and has the further advantages of being non-invasive and quick to perform.

No benefits in any form have been received or will be received from a commercial party related directly or indirectly to the subject of this article.

\section{REFERENCES}

Fairclough J, Colhoun E, Johnston D, Williams LA. Bone scanning for suspected hip fractures: a prospective study in elderly patients. $J$ Bone Joint Surg [Br] 1987; 69-B:251-3.

Lee JK, Yao L. Stress fractures: MR imaging. Radiology 1988; 169: 217-20.

Rizzo PF, Gould ES, Lyden JP, Asnis SE. Diagnosis of occult fractures about the hip: magnetic resonance imaging compared with bonescanning. J Bone Joint Surg [Am] 1993; 75-A:395-401.

\section{POSTERIOR REATTACHMENT OF THE TORN ANTERIOR CRUCIATE LIGAMENT}

\section{W. J. LEACH, J. B. KING}

Injury to the anterior cruciate ligament (ACL) may cause knee instability leading to progressive meniscal and articular damage. We describe posterior reattachment of the proximal end of a ruptured ACL; this may occur after a complete tear at or near the femoral insertion.

Patients and methods. From 1986 to 1993 , a total of 400 cases of injury to the anterior cruciate ligament were diagnosed by arthroscopy by the senior author (JBK). Of

W. J. Leach, FRCS Ed, Senior Registrar

Department of Orthopaedics, Southern General Hospital, 1345 Govan Road, Glasgow G51 4TF, UK

J. B. King, FRCS, Senior Lecturer in Orthopaedics

Royal London Hospital, London E1 1BB, UK.

Correspondence to Mr W. J. Leach.

(1)1994 British Editorial Society of Bone and Joint Surgery 0301-620X/94/1R92 \$2.00)

J Bone Joint Surg [Br] 1994; 76-B:159-60.

Received 16 March 1993; Accepted 20 April 1993 these, $11(2.75 \%)$ had a complete tear of the ligament at its proximal end, with reattachment of the end of the distal

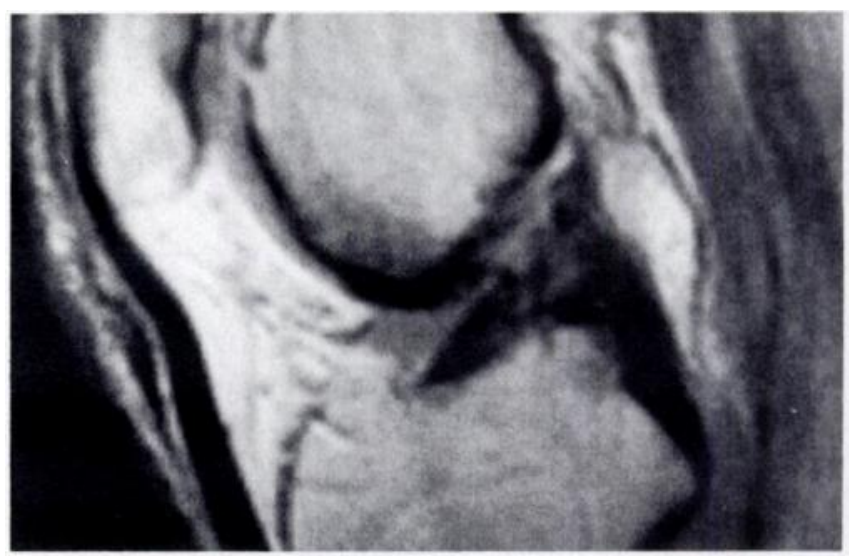

Fig. 1

MRI of the left knee of a 37-year-old man with a negative Lachman and pivot signs showing proximal reattachment of the ACL to the PCL. 